\title{
Eruptive pruritic papular porokeratosis
}

\author{
Wan-Lu Zhang, Dan Huang, Wei Zhang, Ying-Da Wu, Su-Ying Feng, Yi-Qun Jiang, Cheng-Rang Li
}

Department of Dermatology, Chinese Academy of Medical Sciences and Peking Union Medical College, Nanjing, China

Adv Dermatol Allergol 2021; XXXVIII (1): 167-169

DOI: https://doi.org/10.5114/ada.2021.104293

"Eruptive pruritic papular porokeratosis (EPPP)", first proposed by Kanzaki in 1992 [1] and designated as "Inflammatory disseminated superficial porokeratosis (Inflammatory DSP)" by Tanaka in 1995 [2], is a special variant of porokeratosis. The typical clinical course consists of asymptomatic DSP for months to years, followed by the acute pruritic exacerbations, and then subsides spontaneously within 12 months [3]. Histopathological examination reveals the characteristic cornoid lamellae. This paper describes a typical case of EPPP in China and summarizes previously reported EPPP cases.
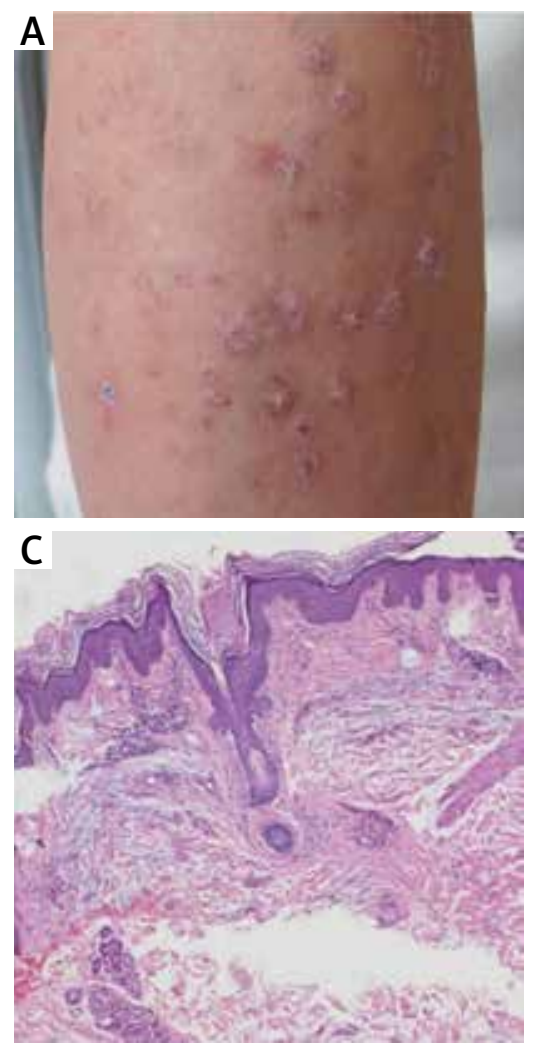

Figure 1. Clinical and histopathological features of the case
Herein we describe a typical case in China - a 68-yearold man with EPPP for 5 years. After the initial 3 years of asymptomatic DSP, typical eruptions such as annular lesions with a raised and sharply marginated keratotic border suddenly presented with recurrent multiple, pruritic, erythematous papules on his extremities and trunk. The lesions subsided in the winter and recurred in the summer. Physical examination revealed numerous nodular erythematous papules like prurigo nodularis lesions (Figure $1 \mathrm{~A}$ ), and hyperpigmented brown macules on his trunk (Figure 1 B). The patient had a history of mild hypertension, no oth-
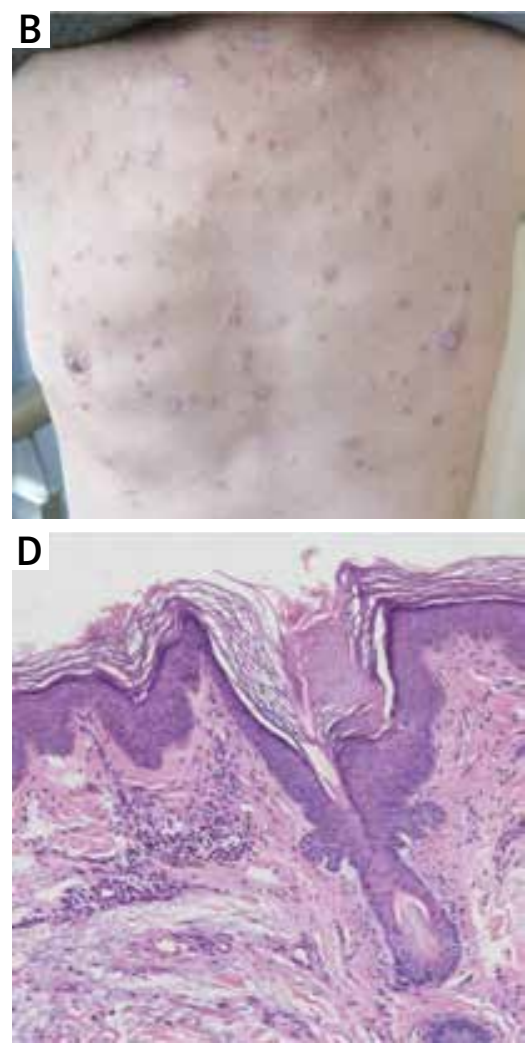

Address for correspondence: Cheng-Rang Li, Department of Dermatology, Chinese Academy of Medical Sciences and Peking Union Medical College, 12 Jiangwangmiao St, Nanjing, China, e-mail: nylcr72@163.com Received: 10.10.2018, accepted: 3.03.2020. 
Table 1. Summary of previously reported cases of EPPP

\begin{tabular}{|c|c|c|c|c|c|c|c|c|}
\hline $\begin{array}{l}\text { Case } \\
\text { no. }\end{array}$ & $\begin{array}{l}\text { Age of } \\
\text { onset }\end{array}$ & Gender & $\begin{array}{l}\text { Pre-existing } \\
\text { asymptomatic } \\
\text { porokeratosis }\end{array}$ & $\begin{array}{c}\text { Period of } \\
\text { pre-existing } \\
\text { lesions }\end{array}$ & $\begin{array}{l}\text { Period of } \\
\text { significant } \\
\text { regression }\end{array}$ & $\begin{array}{l}\text { Other previous } \\
\text { diseases/suspicious } \\
\text { triggering factors }\end{array}$ & $\begin{array}{c}\text { Tissue } \\
\text { eosinophilia }\end{array}$ & Author \\
\hline 1 & 71 & $\mathrm{~F}$ & + & Several years & 5 months & - & + & Kanzaki et al. [1] \\
\hline 2 & 60 & $M$ & + & Nearly 10 years & NM & CVA/drugs & + & Kanzaki et al. [1] \\
\hline 3 & 75 & M & + & Over 10 years & 6 months & Systemic steroids & - & Kanzaki et al. [1] \\
\hline 4 & 78 & M & + & Several years & 3 months & - & - & Tanaka et al. [2] \\
\hline 5 & 69 & M & - & - & 1 year & - & + & Stork et al. [4] \\
\hline 6 & 77 & M & + & 20 years & 4 months & - & + & Ricci et al. [5] \\
\hline 7 & 50 & M & + & 10 years & NM & - & - & Kang et al. [6] \\
\hline 8 & 74 & $M$ & + & 3 years & 2 months & $\begin{array}{c}\text { Cerebral and } \\
\text { myocardial infarction, } \\
\text { diabetes, gout, and } \\
\text { prostatic hypertrophy }\end{array}$ & + & Makino et al. [7] \\
\hline 9 & 82 & M & + & 1 years & 6 months & - & - & Kanekura et al. [8] \\
\hline 10 & 71 & $\mathrm{~F}$ & + & 35 years & NM & - & + & Klein et al. [9] \\
\hline 11 & 84 & M & + & 3 years & 1 month & Colon cancer & + & Choi et al. [10] \\
\hline 12 & 68 & M & + & 4 months & 2 months & - & + & $\begin{array}{c}\text { Wakatabi et al. } \\
\text { [11] }\end{array}$ \\
\hline 13 & 63 & M & + & Over 13 years & NM & - & - & Tee et al. [3] \\
\hline 14 & 77 & $\mathrm{~F}$ & + & Over 20 years & NM & - & + & $\begin{array}{c}\text { Yamamoto et al. } \\
{[12]}\end{array}$ \\
\hline 15 & 80 & M & + & 2 years & NM & $\begin{array}{l}\text { Hypertension and } \\
\text { hyperuricemia }\end{array}$ & - & Inazawa et al. [13] \\
\hline 16 & 63 & $\mathrm{~F}$ & + & 3 years & 2 months+ & $\begin{array}{l}\text { Basedow's disease } \\
\text { and oral thiamazole }\end{array}$ & - & Patrizi et al. [14] \\
\hline 17 & 68 & M & + & 3 years & Up to now & Hypertension & - & Present case \\
\hline
\end{tabular}

F-female, $M$-male, +-positive, --negative, NM-not mentioned, CVA-cerebrovascular accident.

er relevant diseases and he was not on medication. Biopsy specimen of a reddish papule on his right upper limb did not show the granular layer and patchy parakeratosis of keratinocytes in the characteristic cornoid lamellae (Figure 1 C). Mild focal lymphocytes (without eosinophils) infiltrates around the blood vessels in upper dermis (Figure 1 D).

Based on the above symptoms, the patient was definitely diagnosed as EPPP. These pruritic papules did not respond well to topical steroids or oral antihistamines. Interestingly, as the winter progressed, the papules levelled off and the itching was reduced, leaving behind some brownish non-inflamed patches in the follow-up.

By analysing 17 cases of EPPP including the one reported here, we found that EPPP might be manifested with the following characteristics (Table 1 [1-14]): (1) history of pre-existing porokeratosis varied from months ( $>2$ months) to several years except 1 patient who had no pre-existing lesions and no tendency to spontaneous resolution in a 16-month follow-up [4]; (2) less than half of patients had other pre-existing diseases or suspicious triggering factors, including cardiovascular disease, medication history, autoimmune disease, cancer or others;
(3) elderly males might be the susceptible population. The mean age of 17 patients was 71 years, including 13 males in contrast to 30-40 years at onset and the $1: 3$ ratio of male : female for the classic porokeratosis [11]; (4) the typical clinical case presents with sudden multiple erythematous papules, accompanied by strong itching, followed by asymptomatic porokeratosis skin lesions; (5) with the cornoid lamellae, histological examination revealed the presence of eosinophils infiltration in 9 patients, more than half of the cases; and (6) the eruptions could subside within 12 months spontaneously in the follow-up [3].

The reasons responsible for EPPP sudden appearance are still not clear. And the interventions for this particular type of porokeratosis are identical to the classic DSP. Some therapeutic options were used for acute phase lesions such as topical steroids, 5-fluorouracil, assisted freezing, and laser etc. [4, 5], but the efficacy is unsatisfied. Oral antihistamines can be effective against pruritus.

In conclusion, we reported a Chinese man with typical EPPP characteristics. In low temperatures, the eruption tends to resolve, which might be related to season, sun- 
light, humidity or sweat stimulation. Whereas, the mechanisms and characteristics of EPPP need to be further studied with more similar cases.

\section{Acknowledgments}

We thank Qi Li for helping search the literature. This study was funded by CAMS Innovation Fund for Medical Sciences (grant numbers 2016-12M-1-002), Six Talent Peaks Project in Jiangsu Province (WSN-126) and Technology Foundation for Selected Overseas Chinese Scholar, Ministry of Personnel of China.

\section{Conflict of interest}

The authors declare no conflict of interest.

\section{References}

1. Kanzaki T, Miwa N, Kobayashi T, Ogawa S. Eruptive pruritic papular porokeratosis. J Dermatol 1992; 19: 109-12.

2. Tanaka M, Terui T, Kudo K, Tagami H. Inflammatory disseminated superficial porokeratosis followed by regression. Br J Dermatol 1995; 132: 153-5.

3. Tee SI, Chong WS. Eruptive pruritic papular porokeratosis. Indian J Dermatol Venereol Leprol 2012; 78: 758-60.

4. Stork J, Kodetova D. Disseminated superficial porokeratosis: an eruptive pruritic papular variant. Dermatology 1997; 195: 304-5.

5. Ricci C, Rosset A, Panizzon RG. Bullous and pruritic variant of disseminated superficial actinic porokeratosis: successful treatment with grenz rays. Dermatology 1999; 199: 328-31.

6. Kang BD, Kye YC, Kim SN. Disseminated superficial actinic porokeratosis with both typical and prurigo nodularis-like lesions. J Dermatol 2001; 28: 81-5.

7. Makino E, Inaoki M, Fujimoto W. Inflammatory stage of disseminated superficial porokeratosis. J Dermatol 2005; 32: 890-3.

8. Kanekura T, Yoshii N. Eruptive pruritic papular porokeratosis: a pruritic variant of porokeratosis. J Dermatol 2006; 33: 813-6.

9. Klein N, Enk A, Hartschuh W. Inflammatory stage of disseminated superficial porokeratosis in a 71-year old patient. Hautarzt 2009; 60: 420-3.

10. Choi KH, Kim TY. A case of inflammatory disseminated superficial porokeratosis in a colon cancer patient. Ann Dermatol 2009; 21: 150-3.

11. Wakatabi K, Kakurai M, Yamada T, et al. Inflammatory disseminated superficial porokeratosis with an unusual clinical feature of the pruritic, erythematous papules preceding annular brownish pigmentation. J Dermatol 2012; 39: 946-8.

12. Yamamoto T, Furukawa H, Ohtsuka M. Amyloid deposition in disseminated superficial porokeratosis with inflammatory stages. J Dermatol 2013; 40: 1059-60.

13. Inazawa M, Satoh T, Yokozeki H. Hyperkeratotic variant of inflammatory disseminated superficial porokeratosis with lichenoid reaction and extensive amyloid deposition. Int J Dermatol 2014; 53: e94-5.

14. Patrizi A, Virdi A, Misciali C, Bardazzi F. Eruptive pruritic papular porokeratosis in a Caucasian woman: a transient inflammatory stage of porokeratosis. G Ital Dermatol Venereol 2017; 152: 529-31. 